\title{
Including the Voices of Librarians of Color in Reference and Information Services Research
}

\section{Amy VanScoy and Kawanna Bright}

Amy VanScoy (vanscoy@buffalo.edu) is Assistant Professor, Library and Information Studies, Department of Library and Information Studies, State University of New York at Buffalo. Kawanna Bright (kawanna.bright@ du.edu) is a doctoral student in the Department of Research Methods and Statistics at the University of Denver.

This work was supported by an American Library Association Diversity Research Grant.
Reference \& User Services Quarterly vol. 57, no. 2, pp. 104-114 (c) 2017 American Library Association. All rights reserved.

Permission granted to reproduce for nonprofit, educational use.
Librarians of color make up a small proportion of information professionals, but their perspectives should still be included in theory and best practices. This study seeks to create an inclusive understanding of reference and information service (RIS) by exploring the experience of RIS for librarians of color. Using interpretative phenomenological analysis, the experience of RIS for eight librarians of color, from various ethnic groups and types of libraries, is analyzed. Five themes of experience emerged from the analysis: uniqueness and difference; broad range of professional skills; messiness and beauty of the human interaction; working in a web of outside forces; and learning, growth, and change. In relation to prior research, findings show that these librarians of color experience reference and information work as multifaceted and user-focused, in common with librarians in general. However, they have unique experiences of reference and information services work because of microaggressions and discrimination and because of their focus on serving as a role model or mentor.

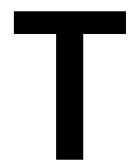

he community of information professionals represents a broad range of identities, abilities, and talents. While they may still be underrepresented in the profession, librarians from diverse ethnic groups should still be contributing their perspective to theory development and best practices. Professionals from diverse backgrounds make unique contributions to the profession, enriching it with a wider variety of perspectives and ideas. In addition, professionals from all ethnic groups must feel that their perspectives and values are reflected to feel fully included within the community of professionals.

To complement existing research in reference and information service (RIS) that focuses on the behavioral aspects of RIS, such as the educator's model of the RIS process, ${ }^{1}$ the content/relational model, ${ }^{2}$ or the traditional model of the steps of the reference interview, ${ }^{3}$ it is important to conduct research on the practitioner perspective of RIS to identify the thoughts and feelings that motivate these behaviors. Study of the practitioner perspective must include a diverse group of professionals to develop an inclusive understanding of RIS for practitioners. However, professionals representing diverse ethnic groups can be difficult to access because they represent a minority of professionals, making up only 12 percent of library professionals in the United States. ${ }^{4}$ As such, all the voices of the diverse community of practitioners are not often heard. 
Librarians from underrepresented groups within the profession may have different ways of understanding their work-different approaches, ways of thinking or ways of measuring success. These new perspectives could reenergize a traditional library practice that has been constructed mainly from the perspective of the majority group. In addition, our understanding of RIS should be an inclusive one, allowing professionals from all backgrounds and orientations to feel that they are represented. This study moves one step forward in creating this inclusive understanding.

The broad problem addressed in this study is the misunderstanding or oversimplification of the work that professionals do in responding to or anticipating user needs. The concept of RIS became entrenched in the idea of looking up facts or locating articles-information seeking tasks that were a challenge in the past, but are much easier today. As a result, the work of information service professionals has evolved, but this has not necessarily been reflected in discussion of or models of the work. The profession defines the work as a series of measurable behaviors that don't reflect the professional judgment and vast expertise necessary to assist users with information seeking and use.

In recent years, some progress has been made toward better defining the reference and information services work that professionals do. The interplay between various competing priorities of the work has been explored, ${ }^{5}$ as well as the constraints and challenges that require professional judgment and expertise. ${ }^{6}$ As this progress is made, a new problem emerges about whether this conceptualization of RIS represents the experiences of all professionals.

The profession suffers from a lack of diversity, which creates a strong majority perspective in information services work. Although librarians clearly value diversity and inclusion, their practice has not been much influenced by diverse perspectives. Concepts such as objectivity and neutrality have been challenged as White majority concepts, as have sacred behaviors, such as smiling and making eye contact. ${ }^{8}$ As a result, the profession focuses on the values and priorities of the large majority, while ignoring those of the very small minority and exacerbating the lack of inclusivity in the profession.

This study aims to create a more inclusive conceptualization of RIS by surfacing the voice of ethnic minority librarians. Deliberately seeking out librarians of color and exploring their conceptualization of the work will result in an understanding of the experience of RIS that is more inclusive.

The aims of the study are to understand the experience of RIS for professionals whose voices have not been heard, and to explore whether and how these professionals' experience of difference affects their RIS practice.

Through a qualitative, phenomenological study, the voices of professionals that have not yet contributed to an understanding of RIS will be heard. It is an effort to reach beyond librarians from the majority group and to create an inclusive understanding of RIS.

\section{LITERATURE REVIEW}

While the job expectations for minority librarians are no different from those of their white counterparts, research on the experiences of minority librarians has shown that their experiences are different and should be studied. ${ }^{9}$ Reviewing research on the experiences and attitudes of librarians indicates that racial or ethnic demographic information of participants is either not collected or not included in the final report. Most research on minority librarians has focused on two distinct areas: recruitment/retention ${ }^{10}$ and leadership. ${ }^{11}$ The scholarship in this area has been criticized as overemphasizing demographic trends, lacking in original research, and focusing too narrowly on academic research libraries. ${ }^{12}$

The research on race and ethnicity in RIS has tended to focus on service provision for users of color rather than on the perspective of the service provider. Some examples of this research include information behavior of immigrants, ${ }^{13}$ effectiveness of reference service to international students, ${ }^{14}$ equality of digital reference service to various ethnic groups, ${ }^{15}$ and the influence of race and ethnicity on service provider approachability. ${ }^{16}$ Taking a different perspective, Brook, Ellenwood, and Lazzaro used critical discourse analysis of spaces, staffing, and RIS-related competency documents to demonstrate the influence of the majority perspective of RIS on reference practice. ${ }^{17}$ They analyzed the critical RIS concepts of approachability, responsiveness, and objectivity through the lens of racism and a culture of Whiteness, arguing that the profession's definitions of these concepts reflect and reinforce the White perspective.

This study specifically addresses the concept of RIS from the practitioner perspective. Among the small body of work on practitioners' conceptualizations of RIS is an informal observation of the "practical wisdom" of reference librarians, ${ }^{18}$ studies of community health information librarians, ${ }^{19}$ and studies of reference archivists. ${ }^{20}$ Three recent phenomenological studies have focused on the experience of RIS or academic librarians: studies of academic reference librarians in Israel, ${ }^{21}$ the United States, ${ }^{22}$ and a study of academic librarians in the United States with a focus on communication overload. ${ }^{23}$ Although these studies have begun to construct a picture of the experience of RIS from the practitioner perspective, most of them focused on academic librarians and none of them used diversity as a criterion in participant selection.

The value of studying the practitioner perspective of professional work has been demonstrated in other professions, often drawing on the work of Schön who perceived the practitioner as an active creator of professional knowledge, particularly through reflection. ${ }^{24}$ This body of research has proved useful in understanding the work of professionals and improving professional education and training in areas such as teaching, ${ }^{25}$ nursing, ${ }^{26}$ and counseling. ${ }^{27}$ Theorists, practitioners, and educators in other disciplines have benefited from this work, as they could in LIS, as well. 


\section{FEATURE}

\section{METHOD}

Interpretative phenomenological analysis (IPA) was used to explore the participants' experience of reference and information services. ${ }^{28}$ IPA is a phenomenological approach that, like other phenomenological methods, focuses on understanding the experience of a phenomenon for a group of participants. IPA is also idiographic, however, meaning that each participant's individual experience is valued and interpreted during analysis. Thus, IPA is differentiated from other phenomenological methods by its attempt to identify differences, as well as commonalities of experience. This focus on differences and commonalities of experience seemed particularly appropriate to the research aims of the study.

Although there are few studies in LIS that use this method, it has been used recently to explore a variety of topics in information science, including how Catholics experience the Bible as a source of religious information, ${ }^{29}$ the information behavior of birthmothers relinquishing a child for adoption, ${ }^{30}$ how people experience documents, ${ }^{31}$ and the lived experience of information services work. ${ }^{32}$

Like grounded theory studies, IPA studies are generally not guided by a theory at the outset-existing theory is introduced at the interpretation phase. ${ }^{33}$ However, in this study, critical race theory influenced study design. ${ }^{34}$ Assumptions from critical race theory that are embedded in the project design include the assertion that race affects the experience of RIS for librarians of color and that their voices provide critical contributions to an understanding of RIS.

\section{Participants}

Once ethics board approval was secured, purposive sampling was used to recruit participants from different ethnic groups. Inclusion criteria were designed to recruit participants with enough RIS experience to have data to share about the phenomenon. Participants must have had at least two years of professional RIS experience, RIS as a significant part of their job responsibilities, and self-identified as a librarian of color.

Potential participants were contacted by email to ask them to participate in the study. All the original eight potential participants contacted by the researchers chose to participate.

The eight participants included four women and four men. The participants self-identified as African American, South Asian, and Latinx, and some offered multiple identities. During the interviews, some participants expressed concern about identifying them by gender and ethnic group in the report of the study. Because the community is so small, some felt that even using a pseudonym that suggested this demographic information could compromise their anonymity. Therefore pseudonyms are not used in the paper to better protect the anonymity of the participants.

Participants were employed in many environments including academic research libraries, community college libraries, special libraries, public libraries, and school libraries. Most participants had worked in multiple library environments throughout their careers, and some were currently working in multiple environments.

\section{Data Collection}

Following IPA procedures, the participants were interviewed about their experience providing RIS and their experience as librarians of color providing RIS. The interviews were semistructured with a list of questions about the participants' experience providing RIS. These questions were used to guide the interview, but the researcher conducting the interview did not interrupt tangents or unprompted comments, opinions, or narratives. Initial interviews lasted for about an hour. The initial interview was recorded and the recordings transcribed. The transcript was reviewed by both researchers and follow-up questions were developed. Each librarian of color participated in a follow-up interview where the researcher asked any questions that were not asked during the initial interview, as well as the follow-up questions. Follow-up interviews were also recorded and the recordings were transcribed.

\section{Data Analysis}

Analysis of the interview data was done using a three-stage process characteristic of IPA analysis, working from thematic analysis of each individual case to a thematic analysis of the group. ${ }^{35}$ First, researchers listened to a single participant's interview recording and read the transcript, noting exploratory comments alongside relevant portions of the transcript. These exploratory comments were focused on describing what the participant said, noting the participant's choice of words and phrases, and noting questions or connections to other ideas. Once a participant's data were thoroughly commented on, the researchers analyzed the transcript and exploratory comments, to develop emergent themes. Emergent themes were noted alongside the relevant portions of the transcript and the exploratory comments. A single transcript typically had one to two hundred emergent themes. Next, the emergent themes for a participant were analyzed to develop superordinate themes - usually six to twelve themes that described the experience of RIS work for that individual. Once superordinate themes were developed for all eight participants, the researchers did a cross-case analysis to develop master themes for the entire group.

Data were analyzed by both researchers, not for purposes of inter-rater reliability, which would not be appropriate for this method, but rather to bring both researchers' perspectives to the interpretation of the data. Each researcher generated exploratory comments individually. Then, emergent themes and superordinate themes were developed together, allowing researchers to raise questions, discuss issues, and interpret the experience of the participants. This joint analysis process was especially important as the 
researchers brought unique perspectives to the project: one researcher identified racially as African American and the other as white. During the analysis process, one researcher sometimes commented on data that the other did not. The ensuing discussion helped to push the analysis beyond mere description, to a higher level of interpretation. Thus the researchers felt that analyzing the data together and taking advantage of two different ethnic perspectives was beneficial to the project.

\section{RESULTS}

Thematic analysis of the data resulted in five themes of the experience of RIS for these librarians of color. There was an overwhelming sense of uniqueness and difference in these participants' experience of work. Positive aspects of this uniqueness included the ability to create special relationships with users of color; negative aspects included diversity fatigue and discrimination. For the participants, the experience of providing reference service was multifaceted and characterized by flexibility, adaptability, and a broad range of professional skills. The experience of the participants emphasized the messiness and beauty of the human interaction that is RIS-including positive and negative emotions, attitudes, and assumptions for both the librarian and the user. There was also a sense that the participants were working in a web of outside forces over which the librarians had no control, including time and staffing constraints, user behaviors, and organizational demands. Finally, learning, growth, and change were also an aspect of the participants' experience of RIS.

\section{Uniqueness and Difference}

A theme of uniqueness and difference appears throughout the participants' accounts of RIS. Participants used phrases such as "unique," "only one," and "set-apartness." One participant described the experience of being a librarian of color as "really neat, weird, awkward experience. Being practically the only one of a very few people of color in that institution." In fact, most participants quantified this uniqueness, often stating that they were the "only one" or "one of four," for example, in the profession with his or her unique characteristics. Although the study intended to focus on participants' experience as librarians of color, most of them expressed multiple ways in which they felt unique in the library environment. One participant described this as "layers of diversity."

Participants were set apart from their majority colleagues in both positive and negative ways. Participants described a unique relationship with users of color, observing that their presence contributed to a more inclusive atmosphere in the library. One participant expressed, "I think there's a level of work that brown and black librarians do inherently, just by being present, by showing up, being available." Another participant described the effect of this visible presence:
So people who may have, who may have looked in the room and not seen themselves represented ... come in now, because they're curious about what I'm doing... I've had people tell me, "You know, I've always walked by this room but I, I've never come in."

They felt that being a librarian of color allowed them to relate better with users of color and to serve them better. Some of the ideas that participants shared about this relationship included the following:

- "an immediate level of comfort"

- "feel some type of connection with me"

- "commonality of language, culture ... just makes that connection so much easier"

- "my skin color allows me to break barriers"

- "they feel like I understand them, so they are more willing to listen to me"

Participants' experience of difference also had negative aspects, however. Many talked about the added burden of being a librarian of color. One area of frustration was the expectation that they "represent the entire minority population," often serving on all diversity-related committees and service initiatives. Some also mentioned feeling that they had to work harder and achieve more than their majority colleagues to, as one participant phrased it, "prove that you deserve it."

In addition, the participants experienced racial microaggressions and discrimination as they provided reference service. Some of these experiences were mild, such as "not being taken seriously" or dealing with legacy stereotypes. One participant provided this perspective:

Because now we're dealing with a perception of maybe who the librarian should be. I feel like that's still going on. That definitely goes on. Some people think you shouldn't have this job possibly. That's never been spoken but that's an impression I feel. You know? 'Cause if we think historically, who were librarians.

Some participants recounted narratives of users explicitly rejecting their attempts to provide service in favor of working with their white colleagues, even when those colleagues were paraprofessional staff. Participants did not express anger or indignation for the users' behavior and sometimes made excuses for it. However, they were clearly emotionally affected, as in one participant's comment, "I felt totally dismissed." Another participant reluctantly added, "That happens very often."

\section{Broad Range of Professional Skills}

For the participants, the experience of providing reference service was multifaceted and characterized by flexibility, adaptability, and a broad range of professional skills. Clearly they experienced their work as professional work, rather than 


\section{FEATURE}

as merely a job-with professional decision-making and expertise. Some expressed a preference for the challenging and complex questions that made use of their professional education. Two examples of this perspective include "if it's a sort of ... in-depth process that I get to . . . apply more of my, like, MLIS type skills ... then I think that leads, and, and it has a positive conclusion, I think that's a ... good interaction" and "it's these very complicated searches, whether it's systematic review or med analysis, so that's exciting because I think it really shows them the value of a librarian."

Most of the participants had worked in various types of libraries and valued different kinds of experiences. One said, "It's just a completely different, but I love it. It's a . . . completely different experience but it keeps me on, on my toes." One participant expressed value in working in different types of libraries, saying "I think it makes us better librarians in my opinion."

There was variation between the participants because they all drew on different goals for the reference encounter and strategies to provide service. This variation resulted in a picture of RIS work as multifaceted and flexible. RIS was characterized as instruction or helping users learn, as providing information, and as serving as a role model or mentor.

All the participants described their work as at least partially instruction. For some, instruction was equivalent to RIS. One participant stated, "I think in my head it's not reference. It's teaching someone how to do research. So I consider it instruction," and others phrased it as, "My job is to teach" and "I'm an instructor in the reference interaction." Even for participants who did not equate RIS with instruction, the instruction component was clear in their descriptions of the work as "teaching them how to find the stuff," "educating students or people," or "I want students to walk away understanding how to use the library."

Although some participants used the word "teaching," the focus seemed to be on user learning. As one participant said, "If the gears start turning, then that's . . satisfying." Another participant expressed a similar satisfaction when they stated, "A good reference interaction, I think it's ... that they learn information literacy skills." Some descriptions of user learning really focused on working to change how users think about their research or library use. This was a common thread throughout the participants' discussions of RIS and helps to clarify what they really mean by instruction. One participant defined RIS by saying, "it's changing the way that they're thinking about the question" and "it's changing the paradigm of how they think." Another described this change as "getting them out of that mindset" and another wanted them to move to "higher-level thinking."

In addition to helping users learn and change their thinking, some participants also valued efficient information provision. One participant said, "I see my role as providing . . . precise and accurate information ... it being authoritative and also being ... relevant to their needs." Another participant described it as "just trying to get them to what they're looking for."
Most of the participants talked extensively about RIS as an opportunity to provide support and mentoring to users. Participants who focused on this aspect of RIS used the words "resource" and "role model." They perceived themselves as an "insider": "one of the things I think that helps me a lot as a librarian providing, you know, service, whether to students of color otherwise, is that I'm also part of the system." Often this was associated with users of color-participants felt that these users may not get this support in other ways and wanted to provide it: "So if they can't get it at home, um, I want them to be able to get it from somewhere. ... So I'm hoping that I, I can be that person." Some of the ways that participants provided this kind of support was connecting users with other campus resources, helping them to understand things from the professor's perspective, and helping them to feel "comfortable" with their research topics.

One participant described it as "kind of a counselor thing." They found themselves talking with users about their personal lives-not something they were completely comfortable with. However, they found value in this for two reasons. First, after a discussion with a colleague, they came to realize that listening to a young person's personal problems met some sort of need for the user. This personal information also helped them to understand users' challenges with using the library. For example, when a student revealed that her siblings would take or destroy the books she checked out from the library, the participant understood why the student only checked out short books that could be read and returned quickly. These realizations led the participant to an expanded definition of their professional role: "seeing myself helping people in other ways outside of my traditional role or what I think it is."

Participants frequently talked about listening as an important component of RIS. Said one participant, "it's the key to providing the correct piece of information." As mentioned above, listening might include listening to information that the participant did not necessarily want to hear: "They want to stay here and talk to me about their personal lives, which I don't hate, but I'm like, am I really helping them?" So the goal for listening was to be able to provide the needed information as well as to help users feel connected. One participant said that listening was important because it "breaks down . assumptions."

When participants were probed to talk more about listening, they described active listening and other behaviors that involved more than simply listening to what users said. Listening included "asking questions" and "using my ears and my eyes." One participant explained, "I'm listening to what they're saying and things they're not saying. And then plugging in questions ... and draw more information from them."

\section{Messiness and Beauty of the Human Interaction}

The experience of RIS for these professionals was fundamentally a human interaction. This interaction was at times messy-fraught with communication challenges, negative 
emotions, and conflicting needs. But it was also beautifulwith the development of fulfilling relationships, success in shared goals, and positive feelings for both the practitioner and the user.

Participants were keenly aware of RIS as a relationship between two individuals. The development of connection and relationship was important, desired, and nurtured. One participant emphasized the role of making connections as part of their job: "One of the great things about, to me, about doing a good reference interview is ... making that further connection." Some relationships appeared to grow out of users having bad experiences with other librarians or other service providers. By having good experiences with the librarian, the user developed trust in the librarian and returned to them when they needed assistance. Participants did emphasize that the librarian could still "be effective without it having to become this deeper thing" and that making a connection and creating a relationship was not the same as creating a friendship. One participant made this clear when they stated that "it doesn't mean that we always have to be friends and best buddies ... not that you have to be best friends but maybe in your reference interview, getting to know them a little bit."

The importance of trust and comfort were frequently mentioned by participants. Trust was often indicated as a conduit for these human interactions and often seen through a user's confidence or belief in the skills of the librarian. One participant felt that this trust led to the user being more likely to listen to the librarian and felt that the user's "belief in me makes it easier for me to guide them and tell them things. Like they feel like I understand them so they are more willing to listen to me."

As part of building trust, most participants also talked of the need to make users feel comfortable within the reference interaction. One method for making users comfortable employed by one participant was humor. Humor was a way to break the ice with the user at the beginning of the interaction, and make them comfortable enough to "let their guard down." One participant stated, "If I can get you comfortable with humor, I am more than halfway there." Cultural identification was also seen as connected to comfort level. One participant reported an "immediate comfort level with African American students."

Emotions were a frequent component of participants' accounts of experience: negative ones leading to uncomfortable and "messy" experiences, positive ones leaning toward the "beautiful." Participants mentioned fear, anger, and frustration. Fear was also mentioned for users: "A freshman regardless of race is going to be fearful of stepping up and asking this quote unquote stupid question" and "asking for help is really difficult." Participants mentioned user anger and their resulting discomfort: "If any of them ever get angry obviously it becomes awkward and difficult" and "sometimes people are gonna be angry and you don't even know why." Two of the participants talked about their desire to remove themselves from emotionally awkward interactions. Said one participant: "I will help a student as much as I can with as much passion as I have, regardless of the topic. But if I'm not comfortable with that student's behavior or the situation that I'm in, I just want to get away as fast as possible."

This sentiment was echoed by another participant: "I don't feel like I handled it very well, but again, because of my own discomfort. ... I just wanted to cut it short and get that person out and away from me."

Affective experiences could also be positive, however, including happiness and excitement. For those who felt positive emotions, these emotions were often tied to whether the librarian felt the interaction was successful. One participant noted that a user "walked away very happy and she got the help that she needed." Another talked about helping a user locate needed information and followed with "it's just a ... weird, happy feeling."

\section{Working in a Web of Outside Forces}

The theme of a broad range of professional skills focuses on the internal aspects of RIS work, but the participants also talked extensively about the challenging context in which they tried to practice these skills. Their practice was highly affected by many factors beyond their control, giving a sense of working in a web of outside forces that created challenges and restrictions. Talking about all these factors together, one participant said, "Depending on the situation, depending on the topic, depending on how many people are waiting for me . . . there's so many things at play."

Participants talked extensively about the constraints of time on their practice. They talked about lines of users and users with deadlines, for example. They talked about "interruptions" and "deadlines" and "triage." This time constraint affected how they delivered RIS. One participant explained, "Of course I'm cognizant that if there's a long line waiting, I'm not gonna, 'Hey, tell me your life story!' I'll be more like, 'All right, go. Let's go." Another participant explained, "I should make this a, a learning moment. But the problem I sometimes don't do that is because, well, again, there are time constraints."

Some participants noted organizational issues that constrained their practice. For example, the lack of sufficient human resources was a barrier to accomplishing their work. Participants used terms such as "understaffed," "chronically short-staffed," and "spread so thin." This lack of staffing forced them to turn their focus away from ideal, high-quality practice: "So we're thinking about changing that, especially with having less staff, we have to be more efficient." In addition, participants expressed conflicts between organization values and their individual, professional values: "I guess that's the struggle for me is what I feel that I should be doing as a professional. And what is expected of me and where that meets. And so for me it's a struggle 'cause sometimes I feel like I'm not doing what I was trained or educated to do."

Some participants indicated that the environment in which they worked affected the type of RIS they practiced, 


\section{FEATURE}

including the types of questions they fielded. Speaking about his experience in a special library, one participant said, "I don't answer questions like, you know, 'Do we have this book checked in?' or 'Can you hold, request this book from the central library?' I don't get those questions because there's many layers before they get to me. Whereas [in] a public library, I'm going to be answering those questions."

One participant provided a nice summary: "I mean, I almost don't see any similarity in just the way I'm even approached, the types of questions, the materials ... It's just completely different."

Participants' experience of RIS was also affected by different modes of delivery, such as responding to questions at a typical reference desk, providing consultation in their offices, or responding to text chat questions online. As an example, one participant explained, "The questions that I get in chat are more in-depth and more complicated than the ones that I get in person. Very rarely do you have actual legitimate difficult reference questions in person, or at least that's been my experience. Whereas I've gotten several really complicated questions online. So it tends to be a lot longer .. . each individual interaction tends to be a lot longer."

Another participant discussed the difference between consultations and interactions at the reference desk: "Yeah, they usually ... are longer, they expect me to use my expertise ... and I get to focus on that. As opposed to me just ... having to be prepared for any question of any sort. It's in my office, so I'm more comfortable. Cause . . . I kind of direct the ... thing."

Finally, characteristics of the user or the users' behavior affect the interaction and sometimes prevented participants from providing ideal service. In the academic or special libraries, the discipline of the user was noted: "The life sciences people, it tends to be very ... direct and I don't know if that's because of their discipline. . . As opposed to a nurse that'll come in and they'll have more of a narrative discussion about what their nursing topic is."

Some participants mentioned the challenges of communication or cognitive issues: "Sometimes they don't express themselves well" and, "Because of the disabilities, this person didn't have the cognitive ability to realize that he was being socially inappropriate." And the users' level of interest in information seeking was mentioned multiple times: "You have ones that just want you to, you know, 'Show me this, show me where this book is and, you know, leave me alone.' And then you have others who you have to stay fully engaged with until you know they're fully satisfied with what they were asking for."

\section{Learning, Growth, and Change}

A final theme for the experience of RIS for these participants is learning, growth and change. Although this theme is less critical to their experience than the other themes, it seemed to pervade the experience of all the participants. Participants frequently expressed enthusiasm for learning and discovery.
Said one participant, "There's this element of excitement. I'm gonna learn something!" Some also were enthusiastic about the "surprise" of RIS work: "I kind of like that challenge of alright, I've got this question you, let's see what you can do with it." They were also appreciative of the novelty of the work: "It's just, like, all over the place. But it's . . . very fascinating." Another participant seemed happy to say, "It's never boring. It never gets boring."

They expressed "openness" to new things, also described as "willing to try anything," as well as a value for "lifetime learning." Some of the participants also expressed their enthusiasm for sharing the experience of learning with the user. One participant expressed this as "so we go into this mode of discovery together . . this feeling of passion that I'm gonna learn something too and I'm excited about sharing that with you."

Several talked about how they learn on the job while working with users. They learn new resources or techniques, and they improve as a librarian because of the interactions they have. For one participant, interacting with users was perceived as fundamental to professional development: "You have to ask questions in order for that librarian to become a better librarian. ... They're only as knowledgeable as the questions that the patrons ask."

One of the participants talked a lot about the importance and pleasure of thinking, adding "I feel like that's what I'm getting paid to do, to think." Other participants seemed to reflect about their work experiences, second-guessing their actions and considering that they could have handled something better or asked more questions. They seem thoughtful and reflective about their practice: "I often think to myself 'Am I being a good librarian or a bad librarian?" Some participants talked explicitly about how their practice had changed over time. One talked about his early career focus on "ascertaining what the person needs ... and then connecting them to whatever they need," but later focusing on "chang[ing] the way people think about what questions they have," demonstrating an evolution from meeting a need to helping a user think differently. Another participant recounted that he was not performing very well as a librarian until a user gave him the advice to ask users how they are doing. Once they started making a connection with the users, then they felt that their reviews were more positive.

\section{DISCUSSION}

\section{Themes of the Experience of RIS for Librarians of Color}

Studying the experience of RIS work for librarians of color reinforces findings from previous studies, and it also contributes new insights into reference work. The findings, particularly the theme of a broad range of professional skills, support those of earlier studies that revealed a conceptualization of RIS work as multifaceted, variable, and demanding. ${ }^{36}$ 
Competing conceptualizations of the work-information provision, instruction, and relationship-building-were identified by this study's participants. The "messiness and beauty of the human interaction theme" reinforces findings of previous studies emphasizing the importance of relationships in RIS ${ }^{37}$ and the significant affective aspects of RIS. ${ }^{38}$ Constraints on the reference interaction, particularly that of time ${ }^{39}$ have been noted in other studies, as has the importance of lifelong learning and curiosity. ${ }^{40}$ So there are certainly commonalities of experience, or perhaps an essence of RIS, that is experienced for professionals regardless of racial or ethnic identity.

However, specifically studying librarians of color revealed some aspects of experience that did not surface in earlier studies of the experience of RIS. There seem to be aspects of RIS that are unique for librarians of color. This unique experience reinforces the findings of earlier studies that library work for librarians of color is different from that of their majority colleagues. ${ }^{41}$ Participants may be asked to take on duties that focus on their ethnic identity, rather than their information science expertise, such as chairing a diversity committee, selecting reference materials, or providing liaison services in subject areas that reflect their perceived ethnic identity, such as urban literature or Asian studies. In addition, some of the librarians of color recounted narratives of discrimination by users at the reference service point and all recounted moments of questioning whether they had just experienced racism or not. Brook, Ellenwood, and Lazzaro have argued that racism is inherent in RIS professional practices. ${ }^{42}$ While this racism is not explicit, commonly accepted RIS practices are orientated toward a White majority interpretation of, for example, approachability or professionalism, thus providing a subtle reinforcement of the majority viewpoint and rejection of other definitions of approachability and professionalism. Although not specifically focused on racism, Doherty has also questioned the power relationship between professional and user. He advocates framing this interaction as a reference "dialogue" instead of a reference "interview."

Finally, the findings reveal a unique perspective on RIS not surfaced in previous studies. These participants emphasized the role model or insider orientation toward RIS and the emphasis on trust and comfort in the reference interaction. While these perspectives are not completely absent in the findings of other studies and would likely not be objected to by majority librarians, they have not been emphasized in models and frameworks for RIS. The role of the librarian as role model, insider, or counselor is certainly not new to librarianship. Penland drew on student affairs theory to develop an approach called counselor librarianship; however, this approach has received little attention in subsequent studies and discussion of RIS. ${ }^{44}$ More recently, Chu and Overall have called for more culturally responsive service that focuses on care and user self-empowerment. However, these calls tended to remain part of the diversity literature and have not become part of mainstream discussions of RIS. ${ }^{45}$
The focus on role modeling and mentoring likely stems from participants explicitly expressed empathy for users of color or users who shared similar backgrounds, such as upbringing in a low socioeconomic situation or experience as a first-time college students. It could be argued that this orientation toward RIS is less a characteristic of participants' reference practice and more a characteristic of their ethnic identity. However, considering the arguments by Penland, $\mathrm{Chu}$, and Overall, as well as the expressed professional desire to support all library users, perhaps this orientation is one that all professionals might consider incorporating into their practice? Majority librarians might learn additional practices by listening to their minority colleagues.

Another perspective with which to interpret this aspect of the participants' practice is their sharing of social capital with their users, ${ }^{46}$ especially those with which they feel a kinship due to shared ethnicity or socioeconomic backgrounds. Participants recognized that, in comparison to users, and particularly users of color, they had greater access to campus or community resources and greater understanding of procedures necessary to achieve goals. Of the three forms of social capital described by Kao-obligation and responsibilities, information channels, and social norms ${ }^{47}$-all were present in the participants' accounts of RIS. Social capital has been explored as an aspect of library information services, for example, as a way to articulate the value of interpersonal relationships between librarians and users ${ }^{48}$ and as a lens for exploring liaison librarianship in academic libraries. ${ }^{49}$ Most relevant to the current study are findings that the public library plays a role in building social capital, particularly among disadvantaged populations.$^{50}$ More specifically, Varheim found that first generation Mexican immigrants to the United States who participated in public library services and programs had an increased level of social trust, ${ }^{51}$ an important finding due to the low levels of trust experienced by first-generation immigrants. The findings of these earlier studies support the participants' sense that building relationships with users who they identify as disadvantaged or new to the community or institution is a valuable and effective way to contribute to these users' social capital.

\section{Limitations and Challenges}

As with any small qualitative study, these findings are not generalizable, but rather transferable. In addition, the findings are the researchers' interpretations of the participants' interpretation of experience, not a single objective reality, although attempts were made to follow rigorous research practices. In addition, the study was conducted in the United States with its unique ethnic cultural context. Findings may not be transferable to other cultural contexts. However, future research that explored the commonalities and differences between ethnic majority and minority librarians in countries outside the United States would provide valuable points of comparison and would add a global perspective to diversity research in RIS. 


\section{FEATURE}

A disappointment to the researchers and a clear limitation to the study is the lack of any Native American participants. During the recruitment process, the researchers intended to include this group, but did not locate librarians with significant RIS responsibilities who publicly identified this way. In subsequent presentations, librarians who identify as Native American have approached the researchers and offered to participate in future studies, so future research may want to specifically concentrate on this group. In addition, the focus on racial or ethnic identity, as opposed to the multiple identities expressed by the participants, at times seemed like a forced category and does not address the issue of intersectionality and its effect on RIS.

It should be noted that the small number of minority librarians and their relative exposure in the profession put these participants at greater risk for conflicts of anonymity. Potential participants' discomfort about possibly being identified may make them less willing to speak about their experiences. This reluctance is also compounded by research fatigue ${ }^{52}$ - potential participants' feeling that they are constantly being targeted for research. This will continue to be an issue for small, qualitative studies with librarians from diverse groups, and researchers need to consider this in study design.

There were important data collected during the interview process that were not analyzed for the study. In discussing their careers and worklife, participants often shared data that were not relevant to the RIS-focused aim of the study. They talked about the importance of mentors and their obligation to serve as mentors to other librarians of color, and about organizational issues related to discrimination and microaggressions as well as user service and the political and socioeconomic issues in libraries. Although these data seemed important and valuable, it was only analyzed if it related in some way to RIS. This created a mild ethical challenge for the researchers-participants spent significant time and shared intimate and sometimes emotional narratives, generating data that might never be used.

\section{Implications}

Issues raised by the results have implications for librarian research, practice, and professional education. Reaching out specifically to parts of the RIS community that have not been heard results in an enhanced understanding of RIS and supports the value of deliberate inclusion of diverse voices in library and information science research. The results of the study indicate that listening to the voices of librarians that are underrepresented in the profession adds nuance to the existing understanding of RIS from the practitioner perspective. While the experience of RIS for these participants was similar in some ways to those of majority librarians, as revealed in earlier studies, the experience of RIS was also interpreted differently by these participants. Serving as a role model or mentor was clearly important for this group and this may be an orientation toward reference practice that should be included with the more traditional orientations of information provision, instruction, and relationshipbuilding.

Issues raised by the study can help colleagues and managers working with librarians of color better understand the work experiences of these librarians. These librarians may be dealing with negative experiences, such as microaggressions and discrimination. Participants in the study specifically expressed concern about how responsibilities were assigned and increased expectations. But some also expressed appreciation for supportive behaviors from majority colleagues and mentoring from other minority colleagues, emphasizing the positive role that colleagues could play in the experiences of these librarians. Finally, the study can be a springboard for discussion in professional education about the challenges for and contributions of our diverse community of professionals.

\section{Further Research}

The findings suggest that the relationship between a user's ethnic identity and that of the librarian is a concern to explore in more depth. This concept, called "racial/ethnic matching" has been studied in the workplace in general, ${ }^{53}$ it has also been studied in specific professions, such as teaching and counseling. ${ }^{54}$ Participants indicated that their interaction with users from a similar ethnic background was different from their interaction with users from dissimilar backgrounds. Bonnet and McAlexander found differences in perception of approachability of a librarian depending on the ethnic group of the user and the librarian. ${ }^{55}$ Thus the concept of racial/ethnic matching in the reference interaction merits further study. It raises the concern of how to address a user's desire for an ethnically matched librarian when the diversity in the profession is so limited.

This study focused on ethnic identity, but participants clearly demonstrated intersectionality-identifying in multiple ways related to race, ethnicity, and sexual orientation. Intersectionality has not been studied in relation to provision of reference and information service or information behavior, in general, although it has been studied in relation to knowledge organization. ${ }^{56}$ Ettarh argued that a focus on ethnic identity, rather than intersectionality, is limiting the profession's response to its lack of diversity and provides suggestions for developing an intersectional perspective. ${ }^{57}$ Future research should explore the influence of these other identities and the effects of intersectionality on the reference interaction.

\section{CONCLUSION}

The findings of this study offer a conceptualization of RIS work that is complicated, diverse, and ever-changing. In the last few decades, developments in information technology have empowered users to independently search for, locate and use information. Unfortunately, this empowerment has 
provided a false impression that professionals with expertise in information retrieval and information behavior are no longer necessary. Professionals, as well as professional education programs, struggle to combat this impression. Findings from studies like this one, that investigate and articulate the actual work that information professionals do, paint a picture of the work that requires multifaceted expertise and is in demand by users.

Another critical challenge for the profession is the lack of ethnic diversity among librarians. This lack of diversity creates a homogenous "face" for the profession, but also limits unique perspectives that can come from diverse cultures and diverse perspectives on the world. Until this situation improves, the profession must be proactive about surfacing the perspectives of diverse professionals within it. By focusing specifically on librarians from underrepresented ethnic groups, this study surfaced aspects of RIS work that have not been widely discussed. These aspects can contribute to an inclusive conceptualization of RIS that represents the perspectives of all professionals.

\section{References}

1. Denise A. Agosto et al., "A Model of the Reference and Information Service Process: An Educators' Perspective," Reference \& User Services Quarterly 50, no. 3 (Spring 2011): 235-44.

2. Marie L. Radford, "Encountering Virtual Users: A Qualitative Investigation of Interpersonal Communication in Chat Reference," Journal of the Association for Information Science and Technology 57, no. 8 (2006): 1046-59; Marie L. Radford and Gary P. Radford, Library Conversations: Reclaiming Interpersonal Communication Theory for Understanding Professional Encounters (Chicago: ALA Neal-Schuman, 2016).

3. RSS Management of Reference Committee, "Guidelines for Behavioral Performance of Reference and Information Service Providers," Reference and User Services Association, May 28, 2013, http://www.ala.org/rusa/resources/guidelines/guidelines behavioral.

4. "Diversity Counts," American Library Association, 2012, http:// www.ala.org/offices/diversity/diversitycounts/divcounts.

5. Amy VanScoy, "Fully Engaged Practice and Emotional Connection: Aspects of the Practitioner Perspective of Reference and Information Service," Library \& Information Science Research 35, no. 4 (2013): 272-78; Amy VanScoy, "Making Sense of Professional Work: Metaphors for Reference and Information Service," Library \& Information Science Research 38, no. 3 (2016): 243-49.

6. Jenny Bossaller, C. Sean Burns, and Amy VanScoy, "Re-conceiving Time in Reference and Information Services Work: A Qualitative Secondary Analysis," Journal of Documentation 73, no. 1 (2017): 2-17; Jenny Bronstein, "The Role and Work Perceptions of Academic Reference Librarians: A Qualitative Inquiry," portal: Libraries and the Academy 11, no. 3 (2011): 791-811; C. Sean Burns, and Jenny Bossaller, "Communication Overload: A Phenomenological Inquiry into Academic Reference Librarianship," Journal of Documentation 68, no. 5 (2012): 597-617.

7. "Diversity Counts."

8. Freeda Brook, Dave Ellenwood, and Althea Eannace Lazzaro, "In Pursuit of Antiracist Social Justice: Denaturalizing Whiteness in the Academic Library," Library Trends 64, no. 2 (2015): 246-84.

9. Ione T. Damasco and Dracine Hodges, "Tenure and Promotion Experiences of Academic Librarians of Color," College \& Research Libraries 73, no. 3 (2012): 279-301; Antonia Olivas and Richard
$\mathrm{Ma}$, "Increasing Retention Rates in Minority Librarians through Mentoring," Electronic Journal of Academic and Special Librarianship 10, no. 3 (Winter 2009), http://southernlibrarianship.icaap .org/content/v10n03/olivas_a01.html.

10. Ashley E. Bonnette, "Mentoring Minority Librarians Up the Career Ladder," Library Administration and Management 18, no. 3 (2004): 134-39; Joan Howland, "Beyond Recruitment: Retention and Promotion Strategies to Ensure Diversity and Success," Library Administration and Management 13, no. 1 (1999): 4-14; Teresa Y. Neely and Lorna Peterson, "Achieving Racial and Ethnic Diversity Among Academic and Research Librarians: The Recruitment, Retention, and Advancement of Librarians of Color-A White Paper," College E Research Libraries News 68, no. 9 (2007): 562-65.

11. Camila A. Alire, "Diversity and Leadership: The Color of Leadership," Journal of Library Administration 32, no. 3/4 (2001): 99-114; Peggy Johnson, "Retaining and Advancing Librarians of Color," College E Research Libraries 68, no. 5 (2007): 405-17.

12. Mark Winston, "Diversity: The Research and the Lack of Progress," New Library World 109, no. 3/4 (2008): 130-49.

13. Nadia Caidi, Danielle Allard, and Lisa Quirke, "Information Practices of Immigrants," Annual Review of Information Science and Technology 44, no. 1 (2010): 491-531.

14. Ann Curry and Deborah Copeman, "Reference Service to International Students: A Field Stimulation Research Study," Journal of Academic Librarianship 31, no. 5 (2005): 409-20.

15. Pnina Shachaf and Sarah Horowitz, "Are Virtual Reference Services Color Blind?," Library \& Information Science Research 28, no. 4 (2007): 501-20; Pnina Shachaf, Shannon M. Oltmann, and Sarah M. Horowitz, "Service Equality in Virtual Reference," Journal of the Association for Information Science and Technology 59, no. 4 (2008): 535-50.

16. Jennifer L. Bonnet and Benjamin McAlexander, "Structural Diversity in Academic Libraries: A Study of Librarian Approachability," Journal of Academic Librarianship 38, no. 5 (2012): 277-86.

17. Brook, Ellenwood, and Lazzaro, "In Pursuit of Antiracist Social Justice."

18. Sara Fine, "Reference and Resources: The Human Side," Journal of Academic Librarianship 21, no. 1 (1995): 17-20.

19. C. Brandi Borman and Pamela J. McKenzie, "Trying to Help Without Getting in their Faces: Public Library Staff Descriptions of Providing Consumer Health Information," Reference \& User Services Quarterly 42, no. 5 (2005): 133-46.

20. Wendy Duff and Allyson Fox, "You're a Guide Rather than an Expert': Archival Reference from an Archivist's Point of View," Journal of the Society of Archivists 27, no. 2 (2006): 129-53.

21. Bronstein, "The Role and Work Perceptions."

22. VanScoy, "Fully Engaged Practice."

23. Burns and Bossaller, "Communication Overload."

24. Donald A. Schön, The Reflective Practitioner: How Professionals Think in Action (New York: Basic, 1983).

25. D. Jean Clandinin, "Personal Practical Knowledge: A Study of Teachers' Classroom Images," Curriculum Inquiry 15, no. 4 (1985): 361-85; Ardra L. Cole, "Personal Theories of Teaching: Development in the Formative Years," Alberta Journal of Educational Research 36, no. 3 (1990): 203-22; Jeffrey W. Cornett, Catherine Yeotis, and Lori Terwilliger, "Teacher Personal Practical Theories and their Influence upon Teacher Curricular and Instructional Actions: A Case Study of a Secondary Science Teacher," Science Education 74, no. 5 (1990): 517-29.

26. Tom H. Cook, Mary Jo Gilmer, and Carolyn J. Bess, "Beginning Students' Definitions of Nursing: An Inductive Framework of Professional Identity," Journal of Nursing Education 42, no. 7 (2003): 311-17; Laurel E. Radwin, "Knowing the Patient: A Process Model for Individualized Interventions," Nursing Research 44, no. 6 (1995): 364-70. 


\section{FEATURE}

27. Maria Poulou, "Reflections of Pre-service Psychologists on the Role of the School Psychologist," School Psychology International 24, no. 4 (2003): 378-93; David A. Spruill and James M. Benshoff, "Helping Beginning Counselors Develop a Personal Theory of Counseling," Counselor Education and Supervision 40, no. 1 (2000): 70-80.

28. John A. Smith, Paul Flowers, and Michael Larkin, Interpretative Phenomenological Analysis: Theory, Method and Research (Los Angeles: Sage, 2009); Amy VanScoy and Solveig Beyza Evenstad, "Interpretative Phenomenological Analysis for LIS Research," Journal of Documentation 71, no. 2 (2015): 338-57.

29. Tim Gorichanaz, "Experiencing the Bible," Journal of Religious $\&$ Theological Information 15, no. 1/2 (2016): 19-31.

30. Rachel Annette Clemens, "Human Information Behavior, Coping and Decision-Making in the Context of a Personal Crisis: An Interpretative Phenomenological Analysis of the Voices of Birthmothers on Relinquishing a Child for Adoption" (PhD diss., University of North Carolina at Chapel Hill, 2015).

31. Kiersten F. Latham, "Experiencing Documents," Journal of Documentation 70, no. 4 (2014): 544-61.

32. VanScoy, "Fully Engaged Practice."

33. Smith, Flowers, and Larkin, "Interpretative Phenomenological Analysis."

34. Laurence Parker and Marvin Lynn, "What's Race Got to Do with It? Critical Race Theory's Conflicts with and Connections to Qualitative Research Method and Epistemology," Qualitative Inquiry 8, no. 1 (2002): 7-22.

35. Smith, Flowers, and Larkin, "Interpretative Phenomenological Analysis."

36. Bronstein, "Role and Work Perceptions"; Burns and Bossaller, "Communication Overload"; VanScoy, "Fully Engaged Practice"; VanScoy, "Making Sense of Professional Work."

37. Radford, "Encountering Virtual Users."; Radford and Radford, "Library Conversations."

38. Heidi Julien and Shelagh K. Genuis, "Librarians' Experiences of the Teaching Role: A National Survey of Librarians," Library $\&$ Information Science Research 33, no. 2 (2011): 103-11; Miriam L. Matteson and Shelly S. Miller, "Emotional Labor in Librarianship: A Research Agenda," Library \& Information Science Research 34, no. 3 (2012): 176-83.

39. Bossaller, Burns, and VanScoy, "Re-conceiving Time."

40. VanScoy, "Fully Engaged Practice"; VanScoy, "Making Sense of Professional Work."

41. Deborah A. Curry, "Your Worries Ain't Like Mine: African American Librarians and the Pervasiveness of Racism, Prejudice and Discrimination in Academe," Reference Librarian 21, no. 45-46 (1994): 299-311; Joyce K. Thornton, "African American Female Librarians: A Study of Job Satisfaction," Journal of Library Administration 33, no. 1-2 (2001): 141-64.

42. Brook, Ellenwood, and Lazzaro, "In Pursuit of Antiracist Social Justice."

43. John J. Doherty, "Reference Interview or Reference Dialogue?" Internet Reference Services Quarterly 11, no. 3 (2006): 97-109.

44. Patrick R. Penland, Interviewing for Counselor and Reference Librarians (Pittsburgh: University of Pittsburgh,1970), ED 049802.

45. Clara M. Chu, "Transformative Information Services: Uprooting Race Politics" (presentation, Black Caucus of the American Library Association Conference, Las Vegas, July 1999); Patricia
Montiel Overall, "Cultural Competence: A Conceptual Framework for Library and Information Science Professionals," Library Quarterly 79, no. 2 (2009): 175-204.

46. James S. Coleman, "Social Capital in the Creation of Human Capital," American Journal of Sociology 94 (1988): S95-S120.

47. Grace Kao, "Social Capital and its Relevance to Minority and Immigrant Populations," Sociology of Education 77, no. 2 (2004): $172-75$

48. Paul Bracke, "Social Networks and Relational Capital in Library Service Assessment," Performance Measurement and Metrics 17, no. 2 (2016): 134-41.

49. Tim Schlak, "Social Capital as Operative in Liaison Librarianship: Librarian Participants' Experiences of Faculty Engagement as Academic Library Liaisons," Journal of Academic Librarianship 42, no. 4 (2016): 411-22.

50. Catherine A. Johnson, "Do Public Libraries Contribute to Social Capital? A Preliminary Investigation into the Relationship," Library \& Information Science Research 32, no. 2 (2010): 147-55; Catherine A. Johnson and Matthew R. Griffis, "A Place Where Everybody Knows your Name? Investigating the Relationship Between Public Libraries and Social Capital," Canadian Journal of Information and Library Science 33, no. 3-4 (2009): 159-91.

51. Andreas Vårheim, "Trust in Libraries and Trust in Most People: Social Capital Creation in the Public Library," Library Quarterly 84, no. 3 (2014): 258-77.

52. Tom Clark, "'We're Over-Researched Here!' Exploring Accounts of Research Fatigue Within Qualitative Research Engagements," Sociology 42, no. 5 (2008): 953-70.

53. Stacy Blake-Beard et al., "Matching by Race and Gender in Mentoring Relationships: Keeping our Eyes on the Prize," Journal of Social Issues 67, no. 3 (2011): 622-43; James R. Elliott and Ryan A. Smith., "Ethnic Matching of Supervisors to Subordinate Work Groups: Findings on 'Bottom-Up,' Ascription and Social Closure," Social Problems 48, no. 2 (2001): 258-76.

54. For racial/ethnic matching in teaching, see Thomas S. Dee, "Teachers, Race, and Student Achievement in a Randomized Experiment," Review of Economics and Statistics 86, no. 1 (2004): 195-210; Colleen M. Eddy and Donald Easton-Brooks, "Ethnic Matching, School Placement, and Mathematics Achievement of African American Students from Kindergarten through Fifth Grade," Urban Education 46, no. 6 (2011): 1280-99. For racial/ ethnic matching in in counseling, see Raquel R. Cabral and Timothy B. Smith, "Racial/Ethnic Matching of Clients and Therapists in Mental Health Services: A Meta-analytic Review of Preferences, Perceptions, and Outcomes," Journal of Counseling Psychology 58, no. 4 (2011): 537-54; Sung-Man Shin et al., "A Meta-analytic Review of Racial-Ethnic Matching for African American and Caucasian American Clients and Clinicians," Journal of Counseling Psychology 52, no. 1 (2005): 45-56.

55. Bonnet and McAlexander, "Structural Diversity in Academic Libraries."

56. Melodie J. Fox, “Priorities of Arrangement' or a 'Hierarchy of Oppressions?': Perspectives on Intersectionality in Knowledge Organization," Knowledge Organization 43, no. 5 (2016): 373-83.

57. Fobazi Ettarh, "Making a New Table: Intersectional Librarianship," In the Library with the Lead Pipe, July 2, 2014, http://www inthelibrarywiththeleadpipe.org/2014/making-a-new-table -intersectional-librarianship-3/. 